\title{
Retrospective Analysis of Clinico-Epidimological Factors in Prostatic Cancer
}

\author{
Atef Youssef Reyad, Mai Mohamed Ezz El Din, Nesreen Ahmed Mosalam \& Walaa Hatem \\ El Damhogy *
}

Department of Clinical Oncology and Nuclear Medicine, Faculty of Medicine, Ain Shams University

*Corresponding Author: Walaa Hatem El Damhogy, Phone No.: (+2) 01003339504,E-mail: walaa_hatem87@outlook.sa

\begin{abstract}
Background: Prostate cancer is the second most common cancer in men and the seventh leading cause of male cancer death worldwide. It is a highly heterogenous disease with great variability in its clinical course. Treatment options vary depending on age, stage, and grade of cancer, as well as other medical conditions.
\end{abstract}

Aim of study: In this retrospective study we aimed to provide clinico-epidemiological characteristics of prostate cancer and to present different treatment modalities with respect to OS, DFS and PFS.

Patients and Methods: Male patients with localized or metastatic prostate cancer presented to Ain Shams University Hospitals in the period from January 2010, to December 2015. In our study, we reviewed medical records of 101 patients including demographic data and clinic-pathological factors were reported, including age, sex, performance status (ECOG), co-morbidities, personal habits, tumor characteristics, surgery, radical treatment, metastatic treatment, treatment response and survival rates were collected.

Results: Our population under study had a median age of 69 years (range: 42-85), majority of our patients $(94 \%)$ had good ECOG performance status $(\leq 2),(44.6 \%)$ of the patients were presented to us with metastatic disease, most common symptoms at presentation were prostatism in $72.8 \%$ of patients and bony aches in $18.8 \%$. The mean Gleason score among studied population was mean 7.37. 44.6\% of the patients were metastatic at time of presentation. Median overall survival in studied population was 31 months, median PFS of the studied group was 17 months and the median DFS 29 months.

Conclusion: We provide an overview of patients with prostate cancer in a single tertiary institution in Cairo and it was found that lack of patient awareness in most patients leads to their late presentation at time of diagnosis.

Key word: Prostate cancer; Diagnosis; Enzalutamide; Salvage; Egypt

\section{INTRODUCTION}

Prostate cancer is the second most common cancer in men and the seventh leading cause of male cancer death worldwide; as there are an estimated 1,600,000 new cases of prostate cancer and 366,000 prostate cancer deaths annually ${ }^{(1)}$.

Prostate cancer patients have a good survival rate if the cancer is diagnosed at an early stage ${ }^{(2)}$. Survival of cancer patients tends to be very poor in developing countries, due to diagnosis at a late stage and inadequate facilities of treatment ${ }^{(3)}$.

$\mathrm{PCa}$ is usually suspected based on DRE and/or an elevated PSA. Definitive diagnosis depends on histopathological examination. Abnormal DRE is an indication for biopsy, but as an independent variable, PSA is a better predictor of cancer than either DRE or transrectal ultrasound (TRUS) ${ }^{(4)}$.

MRI is the most valuable modality in imaging of prostatic cancer using highresolution $\mathrm{T} 2$ images. It provides the most accurate demarcation of the extent of the primary tumor evaluates extra prostatic extension and confirms the presence of seminal vesicle invasion. It also provides information on tumor volume, Gleason grade, and local and regional stage ${ }^{(5)}$.

There are several promising imaging methods that may improve the staging of prostate cancer soon. Prime among these is the prostate specific membrane antigen (PSMA) PET-CT. A series of high-affinity gallium-68labeled and fluorine-18 (F-18)-labeled ligands have been developed that bind PSMA, an antigen expressed in prostate cancers and their 
metastases. Thus, PSMA PET-CT is a promising method for both lymph node and bony staging ${ }^{(6)}$.

The TNM staging, used in combination with tumor grade and prostate-specific antigen (PSA), is regarded as a well-accepted practice standard for prostate cancer and is used as the basis for guiding treatment decision making ${ }^{(5)}$.

In 2018, the US Preventive Services Task Force (USPSTF) issued recommended to individualize decision-making about prostate cancer screening for men ages 55 to 69 , including informing each man about the potential benefits and harms of screening and eliciting his values and preferences for screening ${ }^{(7)}$.

Treatment options vary depending on age, stage, and grade of cancer, as well as other medical conditions. Patients are diagnosed with early stage disease, for which active surveillance can be a good option. Treatment options include surgery (open, laparoscopic, or robotic-assisted), external beam radiation, or brachytherapy. Hormonal therapy may be used along with surgery or radiation therapy in more advanced cases. Treatment often impacts a man's quality of life due to side effects or complications, such as urinary and erectile difficulties, that may be short or long term. More advanced disease is treated with hormonal therapy, chemotherapy, radiation therapy, and/or other treatments ${ }^{(8)}$.

Radical prostatectomy, cryosurgery and brachytherapy are current salvage treatment options for prostate cancer recurrence after primary radiation therapy. Treatment following disease recurrence after surgery, also can involve the use radiotherapy and $\mathrm{ADT}^{(9)}$.

Historically, the first-generation taxane Docetaxel was standard of care and the only treatment for mCRPC with a survival benefit. From 2010, efforts to expand the treatment landscape for $\mathrm{mCRPC}$ resulted in FDA approval of five more agents which improved survival: sipuleucel-T, cabazitaxel, abiraterone acetate, enzalutamide and radium223. However, it is currently unclear in which order to administer these agents, and many clinical trials now focus on optimizing treatment sequences and narrowing patient selection. Mechanisms of resistance to these agents are a key consideration and an active area of research ${ }^{(10)}$.

The current standard for monitoring includes serum PSA every 6 to 12 months for the first five years of post-treatment surveillance and then annually after that. PSA testing every three months may be recommended for men at high risk of recurrence. Because, on rare occasions, a local recurrence may occur in the absence of an elevated PSA, digital rectal examinations should be done annually. Any new nodule felt on physical exam should raise suspicion of recurrent disease ${ }^{(11)}$.

\section{PATIENTS AND METHODS}

\section{Study population}

Male patients with localized or metastatic prostate cancer presented to Ain Shams University Hospitals in the period from January 2010, to December 2015. The study was approved by the Ethics Board of Ain Shams University and an informed written consent was taken from each participant in the study.

Survival endpoints was calculated as Pazdur $^{(12)}$ :

Overall survival (OS) period was measured as the interval between the pathological diagnosis of the disease and death or date of the last follow-up evaluation.

Disease-free survival (DFS) period was measured as the interval between the pathological diagnosis of the disease and progression of the disease, death or date of the last follow-up evaluation.

Progression-free survival (PFS) period was calculated as the interval between the diagnosis of metastatic disease after receiving first-line treatment and evidence of at least one of the following: biochemical failure; progression either locally, in lymph nodes, or in distant metastases; or death from $\mathrm{PCa}$ or date of the last follow-up evaluation.

\section{Data collection and Statistical Analysis}

Data were collected, revised, coded, tabulated and introduced to a PC using the statistical package for social science (IBM SPSS version 24.0 for windows, 2017). 
Qualitative data were presented as number and percentages while quantitative data with parametric distribution were presented as mean, standard deviations and ranges. Also, the quantitative data with nonparametric distribution were presented as median with inter-quartile range (IQR).

Kaplan Meier analysis with Log rank test was used to assess the factors affecting overall survival and progression free survival among the studied patients.

The confidence interval was set to 95\% and the margin of error accepted was set to $5 \%$. So, the p-value was considered significant as the following:

- $\quad \mathrm{P}>0.05$ : Non-significant (NS).

- $\mathrm{P}<0.05$ : Significant $(\mathrm{S})$.

- $\quad \mathrm{P}<0.01$ : Highly significant (HS).

\section{RESULTS}

The study population consisted of 101 male patients. Their mean age was 69 years (range $42-85$ years) and median of 70 years (IQR 65-74 years). The most relevant comorbidity burden among the study population at time of presentation was hypertension with percent of $53.5 \%$ and $18.8 \%$ of patients were diabetic. Different patients' characteristics were studied as shown in table below.

Table 1: Patients characteristics

\begin{tabular}{|l|l|c|c|}
\hline \multicolumn{2}{|c|}{} & $\begin{array}{c}\text { Total no. } \\
\mathbf{1 0 1}\end{array}$ & $\%$ \\
\hline \multirow{4}{*}{ Age } & Mean \pm SD & $69.17 \pm 8.30$ & \\
\cline { 2 - 4 } & Range & $(42-85)$ & \\
\cline { 2 - 4 } & $\begin{array}{l}\text { Median } \\
(\text { IQR) }\end{array}$ & $\begin{array}{c}70 \text { years }(65- \\
74)\end{array}$ & \\
\hline \multirow{2}{*}{$\begin{array}{l}\text { Marital } \\
\text { status }\end{array}$} & Married & 92 & $\begin{array}{c}91.1 \\
\%\end{array}$ \\
\cline { 2 - 4 } & Widow & 9 & $8.9 \%$ \\
\hline \multirow{4}{*}{ Smoking } & No & 36 & $\begin{array}{c}35.6 \\
\%\end{array}$ \\
\cline { 2 - 4 } & Yes & 65 & $\begin{array}{c}64.4 \\
\%\end{array}$ \\
\hline \multirow{4}{*}{ DM } & No & 82 & $\begin{array}{c}81.2 \\
\%\end{array}$ \\
\cline { 2 - 4 } & Yes & 19 & $\begin{array}{c}18.8 \\
\%\end{array}$ \\
\hline \multirow{3}{*}{ HTN } & No & 47 & $\begin{array}{c}46.5 \\
\%\end{array}$ \\
\cline { 2 - 4 } & Yes & 54 & $\begin{array}{c}53.5 \\
\%\end{array}$ \\
\hline \multirow{2}{*}{$\begin{array}{l}\text { Family } \\
\text { history }\end{array}$} & No & 92 & $\begin{array}{c}91.1 \\
\%\end{array}$ \\
\cline { 2 - 4 } & Yes & 9 & $8.9 \%$ \\
\hline
\end{tabular}

Only nine patients $(8.9 \%)$ had a firstdegree family history of malignancy, only 3 of them were prostate cancer. ECOG performance status among the patients at time of presentation was assessed. The highest percentage sixty-one patients $(60.4 \%)$ were ECOG 1 . Thirty patients $(37.5 \%)$ were ECOG 2 and seven patients (6.9\%) were ECOG 3.

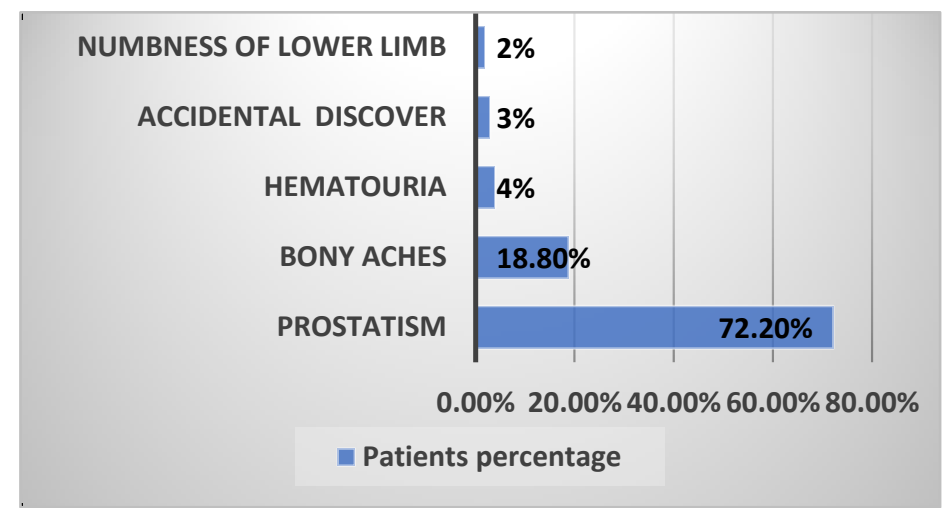

Figure 1: Diagram of descriptive statistics of presentation among studied population.

Patients were presented by variable symptoms; the most common was prostatism in $72.2 \%$ of patients and bony aches in $18.8 \%$ of patients. Forty-five patients were metastatic at time of presentation with percent of $44.6 \%$ while $55.4 \%$ were complaining of localized disease.

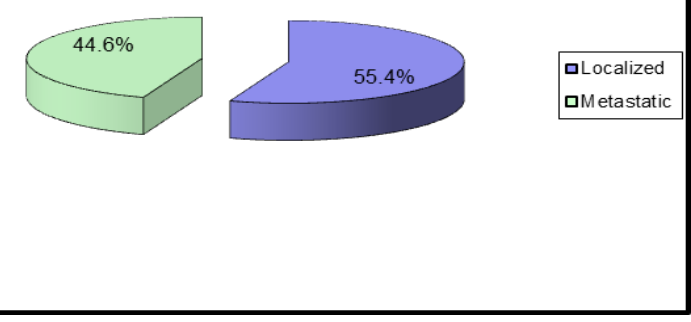

Figure 2: Diagram of stage.

Table 2: PSA level at time of diagnosis among studied population

\begin{tabular}{|l|c|c|c|}
\hline & PSA level & Total no $=101$ & \% \\
\hline \multirow{2}{*}{$\begin{array}{l}\text { PSA at } \\
\text { diagnosis }\end{array}$} & $<10 \mathrm{mg} / \mathrm{dl}$ & 11 & $10.9 \%$ \\
\cline { 2 - 4 } & $10-20 \mathrm{mg} / \mathrm{dl}$ & 26 & $25.7 \%$ \\
\cline { 2 - 4 } & $>20 \mathrm{mg} / \mathrm{dl}$ & 64 & $63.4 \%$ \\
\hline
\end{tabular}

The PSA at time of diagnosis was found to be less than $10 \mathrm{mg} / \mathrm{dl}$ in 11 patients, ranging from 10 to $20 \mathrm{mg} / \mathrm{dl}$ in twenty-six patients and more than $20 \mathrm{mg} / \mathrm{dl}$ in sixty-four 
patients with $63.4 \%$ of total population studied.

Table 3: Gleason score and grade group among studied population

\begin{tabular}{|c|c|c|c|}
\hline \multicolumn{2}{|c|}{} & Total no. $=\mathbf{1 0 1}$ & \% \\
\hline \multirow{3}{*}{$\begin{array}{c}\text { Gleason } \\
\text { score }\end{array}$} & Mean \pm SD & $7.47 \pm 1.18$ & \\
\cline { 2 - 4 } & Range & $6-10$ & \\
\cline { 2 - 4 } & Median & 7 & \\
\hline \multirow{4}{*}{ Grade group } & 1 & 22 & $21.8 \%$ \\
\cline { 2 - 4 } & 2 & 22 & $21.8 \%$ \\
\cline { 2 - 4 } & 3 & 21 & $20.8 \%$ \\
\cline { 2 - 4 } & 4 & 9 & $8.9 \%$ \\
\cline { 2 - 4 } & 5 & 27 & $26.7 \%$ \\
\hline
\end{tabular}

Different lines of treatment among localized prostate cancer was studied and it was found that forty-eight patients who were presented with localized disease received radical radiotherapy with percent of $(85.7 \%)$. Only one patient was under active surveillance and seven patients with percent of $12.5 \%$ underwent radical prostatectomy.

Initially metastatic patient received first line hormonal treatment; as follows: $34.8 \%$ received Biclutamide and Goserline Acetate, $23.9 \%$ of patients underwent surgical castration with Biclutamide, 23.9\% underwent surgical castration only, $13.1 \%$ patients received Goserline acetate only and $4.3 \%$ received Flutamide and Goserline Acetate. The median time to progression among those patients was 16 months.

Table 4: Descriptive statistics of first line management among initially metastatic patients

\begin{tabular}{|c|c|c|c|}
\hline & & $\begin{array}{c}\text { Total no } \\
(46)\end{array}$ & $\%$ \\
\hline \multirow{5}{*}{$\begin{array}{l}\text { First } \\
\text { line } \\
\text { hormon } \\
\text { al } \\
\text { in } \\
\text { metasta } \\
\text { tic PCa } \\
\text { patients }\end{array}$} & $\begin{array}{l}\text { Biclutamide } \\
\text { +Goserline acetate }\end{array}$ & 16 & $\begin{array}{c}34.8 \\
\%\end{array}$ \\
\hline & $\begin{array}{l}\text { Biclutamide }+ \\
\text { surgical castration }\end{array}$ & 11 & $\begin{array}{c}23.9 \\
\%\end{array}$ \\
\hline & $\begin{array}{l}\text { Flutamide }+ \text { Goserline } \\
\text { acetate }\end{array}$ & 2 & $\begin{array}{c}4.3 \\
\%\end{array}$ \\
\hline & Surgical castration & 11 & $\begin{array}{c}23.9 \\
\%\end{array}$ \\
\hline & Goserline Acetate & 6 & $\begin{array}{c}13.1 \\
\%\end{array}$ \\
\hline \multirow{2}{*}{$\begin{array}{l}\text { Time to } \\
\text { progres } \\
\text { sion }\end{array}$} & Median (IQR) & $\begin{array}{c}16(9-26) \\
\text { months }\end{array}$ & \\
\hline & Range & $\begin{array}{l}2-102 \\
\text { months }\end{array}$ & \\
\hline
\end{tabular}

Median overall survival in studied population was 31 months, median PFS of the studied group was 17 months and the median DFS 29 months.

Patients with a good baseline performance status (score $=0$ and 1 ) achieved the highest median OS of 45 and 37 months respectively, while those with a PS score of 2 and 3 achieved 24 and 12 months respectively, with a trend towards significance with P-value 0.004 .

Risk stratification according to D'Amico classification for localized prostate cancer patients was correlated with overall survival in which low risk patients had median OS 41 months and high-risk patients had median OS 23 months which was statistically significant $\mathrm{P}$-value 0.011 and correlated with DFS in which low risk patients had median DFS 33 months and high-risk patients had median DFS 18 months which was statistically significant P-value 0.025.

Patients with stage 2 disease had a statistically significant improved median overall survival of 48 months versus 26 months in those who had stage 4B with a favorable significance $(\mathrm{P}=0.004)$ and those patients with Stage 2 disease had a statistically significant improvement in median DFS of 43 months versus 26 months in those who had stage $4 \mathrm{~A}$ with $\mathrm{P}=0.001$.

\section{DISCUSSION}

The study population number was 101 male patients. The mean age of the studied population was 69 years (range: 42-85) and median age of 70 years. While mean age worldwide is 67 years ${ }^{(3)}$. According to the American Cancer Society ${ }^{(8)}$, the average age at the time of diagnosed is almost 66 years. This is compatible with the well-known characteristics of the disease that usually affects elderly subjects aged 65 years or more and is a rare disease before 50 years of age.

Many co-morbidities were associated with prostate cancer seen in higher age population. Most of the patients were older than 65 years old. In our study, the most relevant co-morbidity among studied population was cardiovascular disease in which $53.5 \%$ of the patients complaining of hypertension and $13.9 \%$ had IHD. Diabetes mellitus (DM) was found in $18.8 \%$ of patients. 
Similarly, Spanish data reported that of all co-morbidities $48.15 \%$ of the patients complained of cardiovascular diseases and $\% 14.41$ complained of DM. Many comorbidities were associated with prostate cancer seen in higher age population ${ }^{(13)}$.

In the United States, most prostate cancers patients are diagnosed because of screening; they are mostly asymptomatic at time of diagnosis. With a small percentage having local symptoms, which usually indicates locally advanced disease ${ }^{(14)}$. While, in our study, most of patients presented with variable symptoms; the most common was prostatism in $72.8 \%$ of patients including irritative and obstructive urinary symptoms and bony aches in $18.8 \%$. The lack of awareness and absence of a screening program led to the late presentation of most our patients.

Similarly, Elabbady and colleagues (15) reported that irritative urinary symptoms were the main presenting complaints in $58 \%$ of their patients and $25 \%$ was asymptomatic and $11 \%$ complained of bony aches and 6\% complained of obstructive urinary symptoms. Same, Ali in 2011 (16), studied clinical presentation, pathological pattern and treatment options of prostate cancer at Al-Azhar University Hospitals in Egypt. He found that lower urinary tract symptoms were more prevalent in group II; prostatic cancer patients from the period from 1995 to 2009; (50 \%), urine retention was the most common presentation in Group I; prostatic cancer patients from the period from 1980 to 1994 ; (51\%).

Similarly, a paper in India,
retrospectively analyzed the clinic
epidemiological of prostate cancer in a single
institution in 2016 it was found that prostatism
was the most common presentation in $75 \%{ }^{(17)}$.

The population-based SEER database in $2018^{(18)}$, local stage corresponds to AJCC stages I and II representing 78\%. Regional stage it includes AJCC stage III and stage IV cancers that have not spread to distant parts of the body and that had spread to nearby lymph nodes (N1) representing $12 \%$. Distant stage describes all cancers that have spread to distant lymph nodes, bone, or other organs (M1) were found in 5\% and unknown stage represented $4 \%$.

Cozar and Colleagues in $2012^{(13)}$ studied the incidence and newly diagnosed patient profile in Spain they found that percentage of patients with localized disease was $89.8 \%, 6.4 \%$ locally advanced and $3.8 \%$ metastatic disease.

Xiao and Colleagues in 2015 studied in a multilevel analysis factors associated with overall survival prostate cancer in Florida. They found that among the 6,457 men diagnosed with prostate cancer in Florida during 2001- 2007, about $12.70 \%$ were diagnosed with advanced stage of prostate cancer. While in our study $21.8 \%$ of patients had local disease, $33.7 \%$ had regional and $44.5 \%$ had distant stage. The lack of awareness and the late presentation of the patient consistent with the fact that the study population from a single tertiary referral unit are the reasons of our results.

James and Colleagues in $2015^{(20)}$ studied the survival in newly diagnosed metastatic patients. Median OS was 42.1 months and median failure-free survival was 11.2 months and the superiority of their results as a result regular follow up to patients under study. Kirby and Colleagues (21) in a systematic review confirms the poor survival with metastatic disease; it was reduced to 9-13 months, confirming the impact of metastases on survival.

In our study, initially metastatic, M1, prostate cancer patients had median overall survival of 26 months (95\% CI 22.16-29.84) compared to non-metastatic patients who had a median OS of 38 months with $\mathrm{p}=0.002$, and the median PFS was found to be 17 months (95\% CI 14.481-19.519) which was statistically significant. Our results could be explained by the heterogeneous population in our study and the lack of regular follow up by our patients.

Only seven patients received Docetaxel as first line chemotherapy with percent of $6.9 \%$, only one of them was metastatic hormonal sensitive prostate cancer in which Docetaxel was added to his hormonal treatment, because of the small number of patients who received chemotherapy, it couldn't be correlated with survival in our study.

Although, Tannock and Colleagues in $2004^{(22)}$, the Phase III clinical trials TAX327 and SWOG 99-16 demonstrated longer OS for patients with mCRPC treated 
with Docetaxel. In the SWOG9916 trial 770 patients with advanced CRPC; the Docetaxel group achieved 17.5 months in OS with $\mathrm{p}=0.02$ and TAX 327 study demonstrated an overall survival benefit of 2.3 months.

Similarly, Chaarted and Stampede studies demonstrated a survival benefit for men with metastatic hormone-sensitive PC (mHSPC) treated with docetaxel plus ADT. Results of the CHAARTED trial were presented in 2014 and published in 2015. Median OS was significantly improved in the ADT plus D arm (57.6 vs 44.0 mo; HR: $0.61 ; \mathrm{p}<0.001)^{(23)}$.

The primary limitation of this study is the retrospective nature of the study. The second limitation is short median follow-up in relation to the long natural history of the disease. The third limitation is that this work is coming from single institution which may not reflect the exact figures about $\mathrm{PCa}$ in our country.

Despite of these limitations, the study was able to maximize the utility of currently available information to present a comprehensive picture of patients' overall survival and different treatment modalities available in our department. Also, it gives idea about the late presentation of this tumor in a considerable number of patients and the importance of a screening program.

\section{CONCLUSION}

In Egypt, due to the lack of patient awareness and access to health care facility, as well as low compliance to regular checkup, routine screening might be of benefit in early detection of prostate cancer patients at earlier stages, hence better treatment outcomes. In addition, awareness against prostate cancer can be generalized in all available mass media, with stress on the targeted patient population.

\section{REFERENCES}

Fitzmaurice C, Allen C, Barber RM et al. (2017): Global, regional, and national cancer incidence, mortality, years of life lost, years lived with disability, and disability-adjusted life-years for 32 cancer groups, 1990 to 2015: a systematic analysis for the global burden of disease study. JAMA Oncology, 3(4): 524-48.

1. Leitzmann MF and Rohrmann $S$ (2012): Risk factors for the onset of prostate cancer: age, location, and behavioral correlates. Clinical Epidemiology, 4:1-11.

2. Jemal A, Bray F, Center MM et al. (2011): Global cancer statistics. CA Cancer J Clin., 61: 69-90.

3. Eggener S, Salomon G, Scardino PT et al. (2010): Focal therapy for prostate cancer: possibilities and limitations. Eur Urol., 58: 57-641.

4. Buyyounouski MK, Choyke PL, McKenney JK et al. (2017): Prostate Cancer Major Changes in the American Joint Committee on Cancer Eighth Edition Cancer Staging Manual. CA Cancer J Clin., 67:245-253.

5. Maurer T, Gschwend JE, Rauscher I et al. (2016): Diagnostic efficacy of (68) gallium-PSMA positron emission tomography compared to conventional imaging for lymph node staging of 130 consecutive patients with inter- mediate to high risk prostate cancer. J Urol., 195: 1436-1443.

6. US Preventive Services Task Force, Grossman DC, Curry SJ et al. (2018): Screening for Prostate Cancer: US Preventive Services Task Force Recommendation Statement. JAMA., 319:1901.

7. American Cancer Society (2015): Cancer Facts \& Figures 2015. Atlanta: American Cancer Society. https://www.cancer.org/.../cancer.../canc er-facts...cancerfacts...figures/2015/cancer-fa

8. Peters M, Moman MR, van der Poel HG et al. (2012): Patterns of outcome and toxicity after salvage prostatectomy, salvage cryosurgery and salvage brachytherapy for prostate cancer recurrences after radiation therapy: a multi-center experience and literature review. World J Urol., 31(2): 403-9.

9. Kapoor A, Christopher W, Shayegan B et al. (2016): Contemporary agents in the management of metastatic castration-resistant prostate cancer. Can Urol Assoc J., 10(11-12): E414-E423. 
10. National Comprehensive Cancer Network (NCCN) (2017): Clinical practice guidelines in oncology: prostate cancer. http://www.nccn.org.

11. Pazdur $R$ (2008): End points for assessing drug activity in clinical trials. Oncologist, 13(12): 19-21.

12. Cózar JM, Miñana B, Gómez-Veiga $F$ et al. (2012): Prostate cancer incidence and newly diagnosed patient profile in Spain in 2010. BJU International, 110(11b): E701-6.

13. Zelefsky MJ, Eastham JA and Sartor AO (2011): Cancer of the prostate. In: DeVita VT Jr, Lawrence TS, Rosenberg SA: Cancer: Principles and Practice of Oncology. 9th ed. Philadelphia, Pa: Lippincott Williams \& Wilkins, pp 1220-71.

14. Elabbady A, Eid A, Fahmy A et al. (2014): Pattern of prostate cancer presentation among the Egyptian population: A study in a single tertiary care center. Cent European J Urol., 67(4): 351-356.

15. Ali M (2011): Clinical Presentation, Pathological Pattern and Treatment Options of Prostate Cancer at Al-Azhar University Hospitals over the Last 30 Years. African Journal of Urology, 17(4): 135-40.

16. Priyadarshi V (2016): Clinical Epidemiology of Carcinoma of Prostate: an Institutional Experience. Urol Nephrol Open Access J., 3 (4): 00089.
17. SEER Database (2018): Cancer Stat Facts: Prostate Cancer. National Cancer Institute. Available at: https://seer.cancer.gov/statfacts/html/pr ost.html

18. Xiao H, Tan F, Adunlin G et al. (2015): Factors associated with overall survival prostate cancer in Florida: a multilevel analysis. Journal of Health Care for the Poor and Underserved, 26(1): 266-77.

19. James ND, Spears MR, Clarke NW et al. (2015): Survival with newly diagnosed metastatic prostate cancer in the "docetaxel era": data from 917 patients in the control arm of the STAMPEDE trial (MRC PR08, CRUK/06/019). Eur Urol., 67: 1028-38.

20. Kirby $\mathrm{M}$, Hirst $\mathrm{C}$ and Crawford ED (2011): Characterising the castration resistant prostate cancer population: a systematic review. International Journal of Clinical Practice, 65(11): 1180-1192.

21. Tannock IF, de Wit R, Berry WR et al. (2004): Docetaxel plus prednisone or mitoxantrone plus prednisone for advanced prostate cancer. N Engl J Med., 351: 1502-12.

22. James ND, Sydes MR, Clarke NW et al. (2016): Addition of docetaxel, zoledronic acid, or both to first-line long-term hormone therapy in prostate cancer (STAMPEDE): survival results from an adaptive, multiarm, multistage, platform randomised controlled trial. Lancet, 387: 1163-77. 